\title{
The Evaluation and Comparison of Trigonal and Linear Tricationic Ion-Pairing Reagents for the Detection of Anions in Positive Mode ESI-MS
}

\author{
Molly M. Warnke, Zachary S. Breitbach, Edra Dodbiba, \\ Eranda Wanigasekara, Xiaotong Zhang, Pritesh Sharma, and \\ Daniel W. Armstrong \\ Department of Chemistry and Biochemistry, University of Texas at Arlington, Arlington, Texas, USA
}

\begin{abstract}
A general and sensitive method for detecting divalent anions by ESI-MS and LC/ESI-MS as positive ions has been developed. The anions are paired with tricationic reagents to form positively charged complexes. In this study, four tricationic reagents, 2 trigonal and 2 linear, were used to study a wide variety of anions, such as disulfonates, dicarboxylates, and inorganic anions. The limits of detection for many of the anions studied were often improved by tandem mass spectrometry. Tricationic pairing agents can also be used with chromatography to enhance the detection of anions. The tricationic reagents were also used to detect monovalent anions by monitoring the doubly charged positive complex. The limits of detection for some of the divalent anions by this method are substantially lower than by other current analytical techniques. (J Am Soc Mass Spectrom 2009, 20, 529-538) (C 2009 Published by Elsevier Inc. on behalf of American Society for Mass Spectrometry
\end{abstract}

$\mathrm{T}$ The analysis of anions is of great necessity and interest in many fields of science. Low levels of organic acids have been determined in a variety of samples such as food, environmental, and biological matrices [1-9]. Some dicarboxylic acids, such as glutaric, fumaric, and adipic acids are marker compounds for certain metabolic disorders and have been determined in urine samples [10]. Aromatic sulfonates are used in many industrial processes and consumer products, such as laundry detergents. Many of these sulfonates end up in waste water and municipal water supplies, and have been determined by various methods [3, 11]. Because of the ramifications of low levels of anions in the environment, fast and effective trace methods of analysis are very important.

Complex environmental sample matrices often require a separation technique to isolate the analyte. Common separation methods include ion chromatography [1, 12-15], ion pair chromatography [3, 11, 16], reverse-phase mode chromatography [17-19], and capillary electrophoresis (CE) $[4,5,20]$. To enhance the spectroscopic detection of anions that do not contain a UV chromophore, some CE and high-performance liquid chromatography (HPLC) methods utilize sample derivatization [21, 22] or indirect UV or fluorescence detection methods [23-25]. Ions have also been detected

Address reprint requests to Dr. D. W. Armstrong, Department of Chemistry and Biochemistry, University of Texas Arlington, Box 19065, Arlington, TX 76019, USA. E-mail: Sec4dwa@uta.edu by ion-selective electrodes and conductivity [26-31]. Mass spectrometry (MS) provides universal detection for anions and is being used more and more, either alone $[13,32]$ or paired with a separation technique [3, $6,18,33]$.

Electrospray ionization (ESI)-MS is a logical choice for ion detection because of the inherent charge state of the analyte. Negative mode ESI-MS is the most common way of detecting anions. Problematically, negative ion mode operation with standard chromatographic solvents, such as methanol and water, can lead to poorer spray stability, corona discharge, and arcing, which ultimately lead to poor detection limits [34, 35]. Halogenated solvents [35-38] or electron scavenging gases [39] can be used to suppress these effects.

Operating in positive mode ESI would help to avoid the stability problems of negative mode ESI-MS and the use of unconventional solvents. A method was developed to detect singly charged anions using positive mode ESI-MS by pairing the anion with a dicationic reagent to create a positively charged complex $[14,15$, 40-43]. There are multiple advantages to this method beyond the use of positive mode ESI-MS. One benefit of monitoring the anion/dication pair is moving the anion to a higher mass region where there is lower background noise. Additionally, anions of low mass are moved well above the low mass cutoff when quadrupole instruments, such as an ion trap, are used. Also, the pairing reagents may be used to differentiate be-
(C) 2009 Published by Elsevier Inc. on behalf of American Society for Mass Spectrometry. 1044-0305/09/\$32.00

doi:10.1016/j.jasms.2008.11.015
Published online November 27, 2008 Received September 26, 2008 Revised November 19, 2008 Accepted November 20, 2008 
tween the analyte of interest and an interference of the same $m / z$ [40].

Most recently, tricationic reagents were paired with divalent anions, which again could be detected as a singly charged complex [44, 45]. The first group of tricationic reagents used as pairing agents were classified as trigonal trications [44]. These trications have fairly rigid structures and provided detection sensitivity enhancement for many of the anions tested. Past results have indicated that rigid dicationic pairing agents did not work as well as more flexible dications [43], so a second class of tricationic reagents was developed. The second group of tricationic reagents is linear and more flexible [46]. The limit of detection (LOD) for many of the divalent anions tested was lower for the linear trications than the trigonal cations [45]. In the present study, the best two trigonal and two linear tricationic reagents from these previous studies are used to determine detection sensitivity for a wide variety of divalent anions. LOD trends for a given tricationic reagent or class and analyte type (e.g., dicarboxylate, disulfonate) would aid in future method development. The use of tricationic reagents in MS-MS and possible dissociation mechanisms are discussed as well. Additionally, these tricationic reagents can be used for the detection of monovalent anions as a doubly charged complex, which has not been previously studied with tricationic reagents. This leads to the possibility of detecting both singly and doubly charged anions using a singular tricationic reagent.

\section{Experimental}

The water and methanol used in these experiments were of HPLC grade and obtained from Burdick and Jackson (Morristown, NJ). Reagent grade sodium hydroxide and sodium fluoride were from Fisher Scientific (Pittsburgh, PA). The anions listed in Tables 1 and 3 were purchased as either the sodium or potassium salt or in the acid form from Sigma-Aldrich, with the exception of butanedisulfonic acid and 1,5-naphthalenedisulfonic acid, which were purchased from TCI America (Portland, OR). Stock solutions $(1 \mathrm{mg} / \mathrm{mL})$ were made weekly and diluted serially for analysis.

The tricationic reagents evaluated in this study, as shown in Figure 1, were synthesized according to previous reports [44-47]. Before analysis, each trication was anion-exchanged to the fluoride form as previously reported [44].

For direct injection analysis, a $40 \mu \mathrm{M}$ tricationfluoride solution was pumped into a Y-type mixing tee at $100 \mu \mathrm{L} / \mathrm{min}$ using a Shimadzu LC-6A pump (Shimadzu, Columbia, MD). Also directed into the mixing tee was a 2:1 mixture of methanol:water at a flow rate of $300 \mu \mathrm{L} / \mathrm{min}$ using the Surveyor MS pump (Thermo Fisher Scientific, San Jose, CA). This set-up leads to an overall solvent composition of 50/50 water/methanol with $10 \mu \mathrm{M}$ tricationic reagent and a total flow rate of 400 $\mu \mathrm{L} / \mathrm{min}$. The six-port injection valve on the mass spectrometer ( $5 \mu \mathrm{L}$ loop) was used for sample introduction.

A Finnigan LXQ (Thermo Fisher Scientific) ESI-MS instrument was used for the analysis of anions in this study. The ESI-MS conditions used were: spray voltage $3 \mathrm{kV}$; sheath gas flow, 37 arbitrary units (AU); auxiliary gas flow rate, $6 \mathrm{AU}$; capillary voltage, $11 \mathrm{~V}$; capillary temperature, $350{ }^{\circ} \mathrm{C}$; tube lens voltage, $105 \mathrm{~V}$. The trication-anion complex was monitored in SIM mode with a width of $5 \mathrm{~m} / \mathrm{z}$ units. This range was chosen to include isotope peaks, and LOD determinations were made from extracted ion chromatograms of the cationanion complex $\mathrm{m} / \mathrm{z}$. For SRM experiments, the isolation width was 1 to 5 units with a normalized collision energy of 30 and an activation time of $30 \mathrm{~ms}$. Data were analyzed using the Xcalibur and Tune Plus software (Thermo Fisher Scientific). The limits of detection were
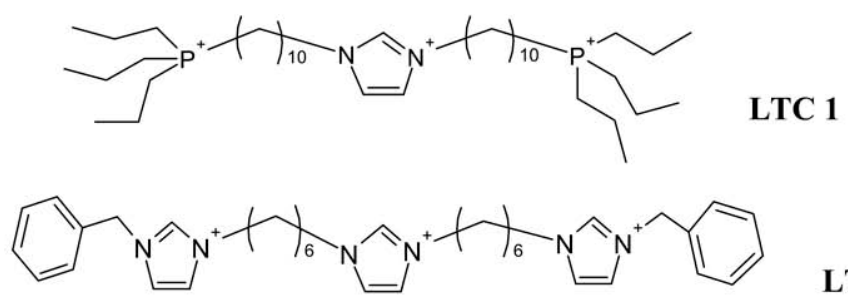

LTC 2
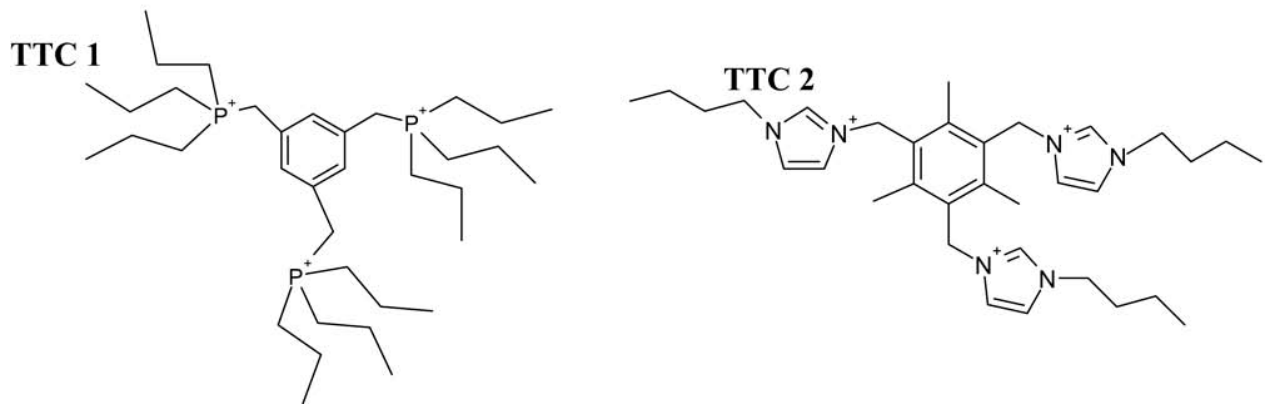

Figure 1. The structures of the four tricationic ion-pairing reagents used in this study. 
determined when multiple injections of a given concentration resulted in a signal-to-noise ratio of three.

For the chromatography experiments, sample introduction was made by a Thermo Fisher Surveyor autosampler ( $5 \mu \mathrm{L}$ injections). The stationary phase used was a Cyclobond $1(25 \mathrm{~cm} \times 2.1 \mathrm{~mm})$ obtained from Advanced Separation Technology (Whippany, NJ). The flow rate was $300 \mu \mathrm{L} / \mathrm{min}$, and the column was equilibrated with $100 \%$ methanol and a step gradient to $100 \%$ water was applied at $5 \mathrm{~min}$. The tricationic reagent $(40 \mu \mathrm{M})$ was added to the column effluent at $100 \mu \mathrm{L} / \mathrm{min}$ via the mixing tee. The mass spectrometer was operated in SIM mode, monitoring the mass of each dianion/trication complex throughout the chromatographic run.

\section{Results and Discussion}

The tricationic reagents used in this study were chosen to represent the best performing trigonal and linear trications used in previous studies [44, 45]. These four tricationic reagents offer a variety of functional groups as well as differences in rigidity. The linear trications contain both an imidazolium core with different chain lengths and terminal charged groups. Linear trication 1 (LTC 1, Figure 1) has $\mathrm{C}_{10}$ linkages between the central imidazolium and tripropylphosphonium (TPP) terminal charged groups. Linear trication 2 (LTC 2, Figure 1) has benzylimidazolium terminal charge groups with a $\mathrm{C}_{6}$ linkage chain. Trigonal trication 1 (TTC 1, Figure 1) has a benzene core with three TPP charged groups. Trigonal trication 2 (TTC 2, Figure 1) consists of a mesitylene core with three $n$-butylimidazolium groups in the 2,4,6 positions.

A variety of divalent anions were chosen to evaluate the ion-pairing performance of the tricationic reagents. The anions can be divided into categories based on their functional groups. The groups are: disulfonates, dicarboxylates, metal containing compounds, other sulfur containing compounds, and miscellaneous compounds. Within the disulfonate and dicarboxylate categories, an effort was made to include compounds with varying chain lengths and functional groups to investigate any effect these might have on limits of detection.

Table 1 shows the 34 divalent anions used in this study and their limits of detection using each of the four tricationic reagents. They are arranged into the anion categories with the lower limits of detection at the top of each category. An examination of the LODs with the bold type-face, which indicate the lowest LOD for each anion, in Table 1 indicates that about $2 / 3$ of the lowest LODs are for the linear tricationic reagents. Additionally, LTC 1 and TTC 1, which are the phosphonium containing reagents, (Figure 1), account for 26 (of 34) of the lowest LODs. The exceptional overall performance of the TPP reagents for this set of divalent anions is in agreement with previous studies [45].

Generally, the disulfonates have lower limits of detection than dicarboxylates. The lowest LODs for the disul- fonates are for dihydroxynaphthalenedisulfonate and $m$ benzenedisulfonate using TTC 1 . The disulfonates with aromatic groups (dihydroxynaphthalenedisulfonate, $m$ benzenedisulfonate, 4-formyl-m-benzenedisulfonate, anthraquinone-2,6-disulfonate) usually had lower LODs than the straight chain disulfonates. Methane, ethane, propane, and butane disulfonic acids were evaluated with each tricationic reagent. There does not appear to be a trend in the detection limit based on the increasing chain length for the disulfonic acids except when using TTC 1, where methane disulfonic acid had a higher LOD than for the longer chain disulfonates. For the disulfonate category as a whole, the trigonal trication reagents performed better than the linear ones.

Two of the other sulfur containing compounds, besides the disulfonates, also shown low LODs. In fact, the LOD for tetrathionate, using LTC 1, is the lowest of all the anions tested when operating in SIM mode (50 $\mathrm{fg}$ ). Tetrathionate and peroxidisulfate were very near the lowest LODs for both LTC 1 and 2, but had LODs higher than most of the disulfonates for TTC 1 and 2 . There appears to be excellent complexation for these sulfur-oxo compounds with the linear trications. Two other sulfur containing compounds (i.e., the bisulfites) had nearly the highest LODs for all of the trications (Table 1).

Among the dicarboxylates studied, dipivaloyl-tartrate has the best LOD when pairing with all of the trications studied and for LTC 1 has a lower LOD than all of the disulfonates. For the tricationic reagents with benzene/ mesitylene cores or charged groups (LTC 2, TTC 1, and TTC 2), the dicarboxylates with nonhalogen chain substitutions (dipivaloyl-tartrate, phenylsuccinate, methylsuccinate, and malate) have lower limits of detection than the straight chain dicarboxylates (Table 1). The halogenated dicarboxylates (chlorosuccinate and dibromomaleate) had lower LODs using the trigonal trications (Table 1). For the straight chain dicarboxylates studied, glutarate, $\left(\mathrm{C}_{5}\right)$, had the lowest limit of detection, followed by pimelate, $\left(C_{7}\right)$, and then adipate, $\left(C_{6}\right)$. With LTC 1, the LOD for adipate is about 7 times higher than for glutarate, though they only differ by one carbon in chain length. For the dicarboxylate category in general, the linear trications outperformed the trigonal ones.

The inorganic compounds studied generally had higher LODs than the organic acids and disulfonates. $\mathrm{ReCl}_{6}$ showed the best results of the inorganic compounds studied and had a limit of detection in the top five for LTC 1, LTC 2, and TTC 2. Two phosphorus containing compounds were also studied. Phenyl phosphate had lower LODs than hydrogen phosphite. This result is in general agreement with earlier work that used dicationic reagents and singly charged anions, which found that more oxidized species had better LODs [42].

The additional application of the tricationic reagent to enhance detection for chromatography is shown in Figure 2. Three dianions (camphorate, phenylsuccinate, 
Table 1. Limits of detection for divalent anions using four tricationic pairing reagents in selected ion monitoring (SIM) mode*

\begin{tabular}{|c|c|c|c|c|}
\hline & \multicolumn{2}{|c|}{ Linear trications } & \multicolumn{2}{|c|}{ Trigonal trications } \\
\hline & $\begin{array}{c}\text { LTC } 1 \\
\text { LOD (ng) }\end{array}$ & $\begin{array}{c}\text { LTC } 2 \\
\text { LOD (ng) }\end{array}$ & $\begin{array}{c}\text { TTC } 1 \\
\text { LOD (ng) }\end{array}$ & $\begin{array}{c}\text { TTC } 2 \\
\text { LOD (ng) }\end{array}$ \\
\hline \multicolumn{5}{|l|}{ Disulfonates } \\
\hline Dihydroxynaphthalenedisulfonate & $7.50 \mathrm{E}-02$ & $5.00 \mathrm{E}-02$ & 7.50E-03 & $1.20 \mathrm{E}-02$ \\
\hline m-Benzenedisulfonate & $2.50 \mathrm{E}-02$ & $5.00 \mathrm{E}-02$ & 8.75E-03 & $1.00 \mathrm{E}-02$ \\
\hline 4-Formyl-m-benzenedisulfonate & $1.25 \mathrm{E}-01$ & $3.75 \mathrm{E}-02$ & $1.00 \mathrm{E}-02$ & $1.50 \mathrm{E}-02$ \\
\hline Naphthalene-1,5-disulfonate & $6.00 \mathrm{E}-02$ & 1.25E-02 & $2.00 \mathrm{E}-02$ & $3.00 \mathrm{E}-02$ \\
\hline Butanedisulfonate & $1.25 \mathrm{E}-01$ & $5.00 \mathrm{E}-02$ & $3.00 \mathrm{E}-02$ & 2.00E-02 \\
\hline Propanedisulfonate & $1.00 \mathrm{E}-01$ & 2.00E-01 & $2.45 \mathrm{E}-02$ & $7.50 \mathrm{E}-02$ \\
\hline Anthraquinone-2,6-disulfonate & 2.50E-02 & $5.00 \mathrm{E}-02$ & $7.50 \mathrm{E}-02$ & $5.00 \mathrm{E}-02$ \\
\hline Methanedisulfonate & $1.00 \mathrm{E}-01$ & 3.00E-02 & $6.00 \mathrm{E}-02$ & 3.00E-02 \\
\hline Ethanedisulfonate & $3.50 \mathrm{E}-02$ & $2.25 \mathrm{E}-01$ & $3.60 \mathrm{E}-02$ & $4.00 \mathrm{E}-02$ \\
\hline \multicolumn{5}{|l|}{ Dicarboxylates } \\
\hline Dipivolyltartarate & $1.75 \mathrm{E}-02$ & 1.25E-02 & $1.50 \mathrm{E}-02$ & $1.50 \mathrm{E}-02$ \\
\hline Camphorate & $6.00 \mathrm{E}-02$ & $1.50 \mathrm{E}-01$ & $6.00 \mathrm{E}-02$ & $5.00 \mathrm{E}-01$ \\
\hline Phenylsuccinate & $1.50 \mathrm{E}-01$ & $7.50 \mathrm{E}-02$ & 5.00E-02 & $1.00 \mathrm{E}-01$ \\
\hline Glutarate & 7.00E-02 & $2.00 \mathrm{E}-01$ & $1.00 \mathrm{E}+00$ & 5.00E-01 \\
\hline Malate & $2.60 \mathrm{E}-01$ & 5.00E-02 & $2.25 \mathrm{E}-01$ & $5.00 \mathrm{E}-01$ \\
\hline Methylsuccinate & $2.00 \mathrm{E}-01$ & 7.50E-02 & $2.50 \mathrm{E}-01$ & $1.00 \mathrm{E}-01$ \\
\hline Fumarate & $1.50 \mathrm{E}-01$ & $4.00 \mathrm{E}-01$ & $1.50 \mathrm{E}+00$ & $7.50 \mathrm{E}+00$ \\
\hline Pimelate & $1.50 \mathrm{E}-01$ & $2.00 \mathrm{E}-01$ & $2.50 \mathrm{E}+00$ & 7.50E-01 \\
\hline Malonate & $2.00 \mathrm{E}+00$ & $1.38 \mathrm{E}+00$ & $8.75 \mathrm{E}-01$ & 3.00E-01 \\
\hline Adipate & 5.00E-01 & 8.00E-01 & $2.25 \mathrm{E}+00$ & $1.50 \mathrm{E}+00$ \\
\hline Dibromomaleate & $8.50 \mathrm{E}-01$ & $1.00 \mathrm{E}+00$ & $1.00 \mathrm{E}-01$ & 1.75E-01 \\
\hline Chlorosuccinate & $3.75 \mathrm{E}+00$ & $1.88 \mathrm{E}+00$ & 2.25E-01 & $9.00 \mathrm{E}-01$ \\
\hline \multicolumn{5}{|l|}{ Metal containing compounds } \\
\hline Hexachlororhenate $\mathrm{ReCl}_{6}$ & $1.50 \mathrm{E}-02$ & $3.00 \mathrm{E}-02$ & $1.50 \mathrm{E}-01$ & $2.00 \mathrm{E}-02$ \\
\hline Chromate $\mathrm{CrO}_{4}$ & $2.50 \mathrm{E}-01$ & $7.50 \mathrm{E}-01$ & $6.25 \mathrm{E}+00$ & 7.50E-02 \\
\hline Molybdate $\mathrm{MoO}_{4}$ & $1.50 \mathrm{E}-01$ & $2.50 \mathrm{E}+00$ & $3.75 \mathrm{E}-01$ & $7.50 \mathrm{E}-01$ \\
\hline Manganate $\mathrm{MnO}_{4}$ & $1.00 \mathrm{E}+00$ & - & $3.75 E-01$ & 8.75E-01 \\
\hline Arsenate $\mathrm{AsO}_{4}$ & 7.50E-01 & $2.25 \mathrm{E}+00$ & $2.50 \mathrm{E}+00$ & $1.00 \mathrm{E}+00$ \\
\hline \multicolumn{5}{|l|}{ Other sulfur compounds } \\
\hline Tetrathionate $\mathrm{S}_{4} \mathrm{O}_{6}$ & $5.00 \mathrm{E}-04$ & $2.25 \mathrm{E}-02$ & $2.50 \mathrm{E}-02$ & $5.00 \mathrm{E}-02$ \\
\hline Peroxidisulfate $\mathrm{S}_{2} \mathrm{O}_{8}$ & $1.20 \mathrm{E}-02$ & $1.65 \mathrm{E}-02$ & $7.50 \mathrm{E}-02$ & $2.00 \mathrm{E}-01$ \\
\hline Succinaldehyde bisulfite & $1.25 \mathrm{E}+01$ & $2.50 \mathrm{E}+01$ & $1.25 \mathrm{E}+00$ & $5.00 \mathrm{E}+00$ \\
\hline Glutaraldehyde bisulfite & $3.50 \mathrm{E}+00$ & $2.50 \mathrm{E}+00$ & $1.75 \mathrm{E}+00$ & $2.50 \mathrm{E}+00$ \\
\hline \multicolumn{5}{|l|}{ Miscellaneous compounds } \\
\hline Phenylphosphate & 4.00E-02 & $1.00 \mathrm{E}-01$ & $7.50 \mathrm{E}-02$ & $5.00 \mathrm{E}-02$ \\
\hline Rhodizonate & $1.05 \mathrm{E}-01$ & $5.00 \mathrm{E}-01$ & $3.75 \mathrm{E}+00$ & $3.75 \mathrm{E}-01$ \\
\hline Hydrogen phosphite & $1.50 \mathrm{E}-01$ & $5.00 \mathrm{E}-01$ & $3.75 \mathrm{E}-01$ & $2.50 \mathrm{E}-01$ \\
\hline Selenite & $1.25 \mathrm{E}+00$ & - & $3.50 \mathrm{E}-01$ & $3.75 \mathrm{E}+00$ \\
\hline
\end{tabular}

* Limit of detection determined where the amount of analyte used results in $\mathrm{S} / \mathrm{N}=3$.

Bold typeface indicates the lowest limit of detection for each anion.

- Indicates that a dianion/trication complex was not observed.

and naphthalene-1,5-disulfonate) are separated using a $\beta$-cyclodextrin stationary phase. The trication is added post-column. The better peak shape for the late eluting naphthalene-1,5-disulfonate peak is likely due to the step gradient employed. The first two peaks are broadened before the mobile phase is changed, while the third peak is eluted by the strong solvent. Chromatographic retention and separation of dianions could be very useful in cases of complex sample matrixes.

The limits of detection for most of the divalent anions could be reduced by using single-reaction monitoring (SRM). Some advantages of SRM are to improve specificity in analysis, to lower noise in the region being analyzed, and/or to eliminate interference by a background ion in the mass spectrometer. In SRM, the dianion-trication complex is trapped, excited, and the transition to a resultant fragment is monitored. SRM analysis was performed for each dianion and the results are shown in Table 2.

For LTC 1, most SRM transitions were to a fragment of the trication. Most of the dianion/trication complexes fragmented to either $m / z 665.5$ [LTC1-2H] ${ }^{+1}$ or $m / z 367.4$ corresponding to the $\mathrm{C}_{10} \mathrm{TPP}$ imidazole (shown in Figure 3a). The inorganic anions, tetrathionate, peroxidisulfate, fumarate, phenylphosphate, and phenylsuccinate did not fragment to $m / z 665$ or 367.4. For these -2 anions, a portion of the dianion was lost and the +1 complex between the trication and the remainder of the dianion was monitored. An example is tetrathionate where the complex fragment monitored $(\mathrm{m} / \mathrm{z}$ 811.6) 


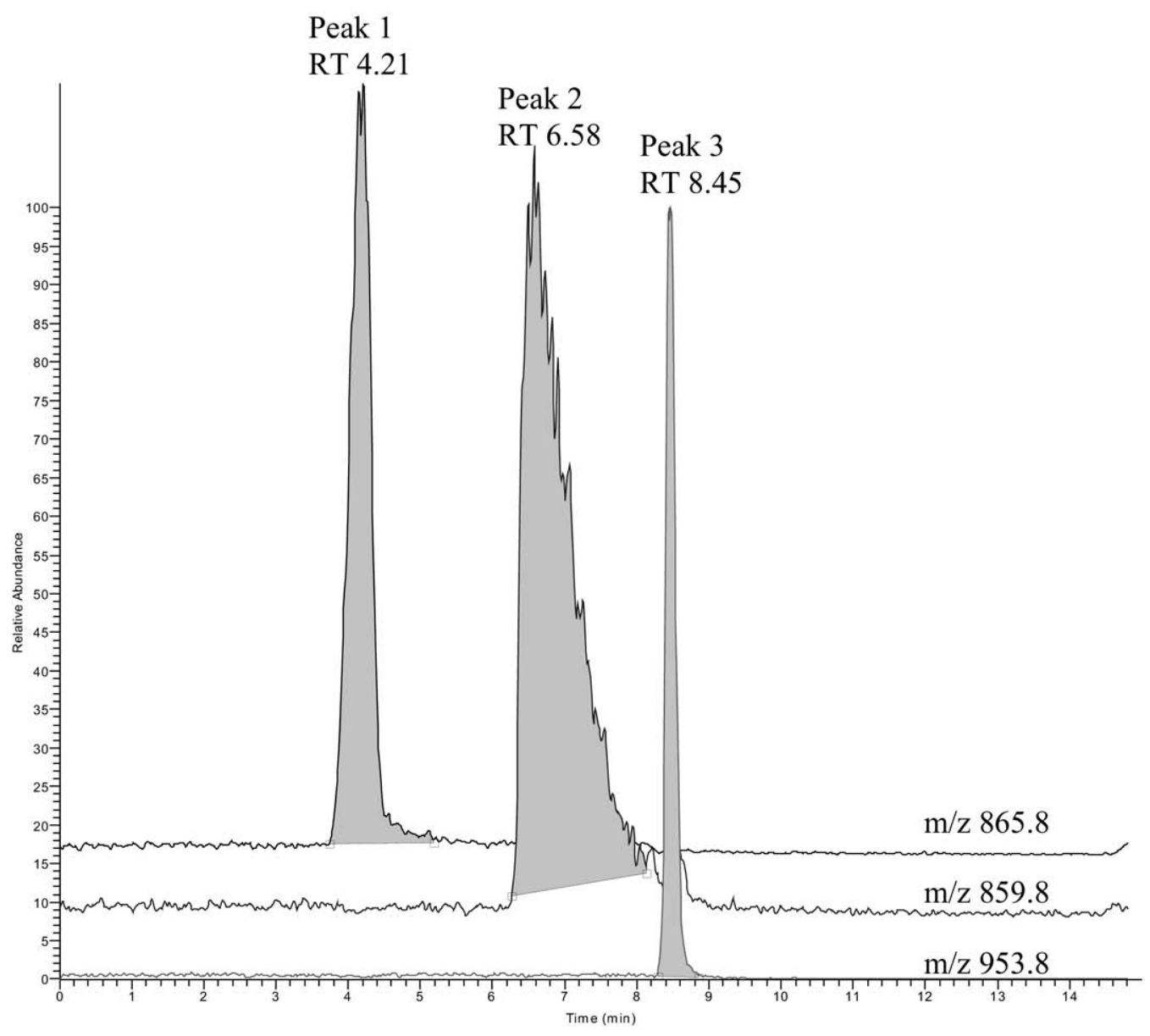

Figure 2. An extracted ion chromatogram representing the LC separation of camphorate (peak 1), phenylsuccinate (peak 2), and naphthalene-1,5-disulfonate (peak 3) with the retention times (RT) also listed. This separation was performed on a $\beta$-cyclodextrin stationary phase $(2.1 \mathrm{~mm} \times 25 \mathrm{~cm})$, which was equilibrated with $100 \%$ methanol. A step gradient to $100 \%$ water was applied at $5 \mathrm{~min}$. The flow rate was $300 \mu \mathrm{L} / \mathrm{min}$ and $40 \mu \mathrm{M}$ LTC 1 was introduced with a tee-piece to the effluent at a flow rate of $100 \mu \mathrm{L} / \mathrm{min}$. The three trication-dianion complex masses were monitored simultaneously in SIM mode.

corresponds with the loss of $\mathrm{SO}_{3}$. The most common fragments for LTC 2, were either the loss of one hydrogen each from two of the imidazolium rings $(\mathrm{m} / \mathrm{z}$ 551.3) or the loss of the benzylimidazolium group (Figure $3 \mathrm{~b}$ ). For the complexes that lost the benzylimidazolium group, the dianion stayed complexed with the remainder of the trication. This unconventional fragmentation occurred with LTC 2 for the inorganic anions, peroxidisulfate, tetrathionate, rhodizonate, phenylphosphate, and dihydroxynaphthalenedisulfonic acid.

The predominant fragment monitored for TTC 1 is the loss of two hydrogens from the methylene carbons between the phosphorus and benzene ring. Only manganate, peroxidisulfate, tetrathionate, hexachlororhenate, and chromate underwent alternate fragmentation. The major fragmentation pathway for TTC 2 is the loss of the butylimidazolium group from the overall complex, so the dianion remains with the rest of the trication. Arsenate, peroxidisulfate, tetrathionate, rhodizonate, hexachlororhenate, glutaraldehyde bisulfate, dihydroxynaphthalenedisulfonic acid, adipate, and pimelate, succinaldehyde bisulfite, and camphorate followed alternate fragmentation patterns with TTC 2.

The group of compounds that had the largest improvements in LOD between SIM and SRM were the disulfonates. With one or more of the trications studied, each disulfonate had its LOD improved by at least an order of magnitude. The disulfonates were the only analytes to follow fragmentation for LTC 1 and LTC 2 as shown in Figure $3 a$ and $b$, respectively. While the largest change in LOD was seen for the linear trications, the trigonal trications had the lowest LOD for five of the nine disulfonates studied.

Chlorosuccinate and dibromomaleate also had interesting fragmentation patterns. In the case of these analytes, the halogen is lost from the anion and remains paired with the trication (or a portion of it). This was seen in our previous study on the linear trications [45]. Figure 4a illustrates a proposed fragmentation pattern for dibromomaleate using TTC 1 . The distinct isotopic 
Table 2. Limits of detection for divalent anions using four tricationic pairing reagent in selected reaction monitoring (SRM) mode*

\begin{tabular}{|c|c|c|c|c|}
\hline & \multicolumn{2}{|c|}{ Linear trications } & \multicolumn{2}{|c|}{ Trigonal trications } \\
\hline & $\begin{array}{c}\text { LTC } 1 \\
\text { LOD (ng) }\end{array}$ & $\begin{array}{c}\text { LTC } 2 \\
\text { LOD (ng) }\end{array}$ & $\begin{array}{c}\text { TTC } 1 \\
\text { LOD (ng) }\end{array}$ & $\begin{array}{c}\text { TTC } 2 \\
\text { LOD (ng) }\end{array}$ \\
\hline \multicolumn{5}{|l|}{ Disulfonates } \\
\hline Dihydroxynaphthalenedisulfonate & $2.75 \mathrm{E}-03$ & $5.00 \mathrm{E}-03$ & $7.50 \mathrm{E}-03$ & $1.20 \mathrm{E}-03$ \\
\hline m-Benzenedisulfonate & 5.00E-04 & $3.00 \mathrm{E}-03$ & $6.25 \mathrm{E}-03$ & $1.25 \mathrm{E}-03$ \\
\hline 4-Formyl-m-benzenedisulfonate & $5.00 \mathrm{E}-03$ & $1.00 \mathrm{E}-02$ & - & $1.50 \mathrm{E}-03$ \\
\hline Naphthalene-1,5-disulfonate & 4.61E-04 & $4.38 \mathrm{E}+00$ & $4.50 \mathrm{E}-03$ & $3.60 \mathrm{E}-03$ \\
\hline Butanedisulfonate & $4.50 \mathrm{E}-03$ & $6.25 \mathrm{E}-03$ & $3.50 \mathrm{E}-03$ & 4.50E-03 \\
\hline Propanedisulfonate & $2.00 \mathrm{E}-02$ & $1.25 \mathrm{E}-02$ & $7.50 \mathrm{E}-03$ & $4.50 \mathrm{E}-03$ \\
\hline Anthraquinone-2,6-disulfonate & $1.13 \mathrm{E}-03$ & 7.50E-04 & $3.60 \mathrm{E}-03$ & $7.90 \mathrm{E}-03$ \\
\hline Methanedisulfonate & $3.25 \mathrm{E}-03$ & 3.15E-03 & $4.50 \mathrm{E}-02$ & 3.00E-03 \\
\hline Ethanedisulfonate & $1.50 \mathrm{E}-03$ & 8.75E-03 & $1.44 \mathrm{E}-02$ & $9.80 \mathrm{E}-03$ \\
\hline \multicolumn{5}{|l|}{ Dicarboxylates } \\
\hline Dipivolyltartarate & $6.25 \mathrm{E}-03$ & 3.75E-03 & $1.00 \mathrm{E}-02$ & $5.50 \mathrm{E}-03$ \\
\hline Camphorate & $4.50 \mathrm{E}-02$ & $4.50 \mathrm{E}-02$ & 3.00E-02 & $2.00 \mathrm{E}-01$ \\
\hline Phenylsuccinate & $1.00 \mathrm{E}+00$ & 7.50E-02 & $1.00 \mathrm{E}-01$ & $2.50 \mathrm{E}-02$ \\
\hline Glutarate & 3.75E-02 & $6.00 \mathrm{E}-02$ & $7.50 \mathrm{E}-01$ & $1.50 \mathrm{E}-01$ \\
\hline Malate & $7.00 \mathrm{E}-02$ & $1.50 \mathrm{E}-02$ & - & - \\
\hline Methylsuccinate & 2.40E-02 & $3.75 \mathrm{E}-02$ & $1.05 \mathrm{E}-01$ & $4.00 \mathrm{E}-02$ \\
\hline Fumarate & $1.00 \mathrm{E}-02$ & $2.25 \mathrm{E}-02$ & $1.50 \mathrm{E}+00$ & - \\
\hline Pimelate & $3.00 \mathrm{E}-02$ & $7.50 \mathrm{E}-02$ & $3.25 \mathrm{E}+00$ & $7.50 \mathrm{E}-01$ \\
\hline Malonate & 1.00E-01 & $1.20 \mathrm{E}-01$ & $3.00 \mathrm{E}-01$ & $5.00 \mathrm{E}-01$ \\
\hline Adipate & $1.20 \mathrm{E}-01$ & $2.25 \mathrm{E}-01$ & $2.25 \mathrm{E}+00$ & $1.50 \mathrm{E}+00$ \\
\hline Dibromomaleate & $7.50 \mathrm{E}-02$ & $3.00 \mathrm{E}-02$ & $3.50 \mathrm{E}-02$ & $2.50 \mathrm{E}-03$ \\
\hline Chlorosuccinate & $1.50 \mathrm{E}+00$ & $3.75 \mathrm{E}+00$ & 4.50E-01 & - \\
\hline \multicolumn{5}{|l|}{ Metal containing compounds } \\
\hline Hexachlororhenate $\mathrm{ReCl}_{6}$ & 2.00E-03 & $3.00 \mathrm{E}-03$ & $1.00 \mathrm{E}-02$ & $2.00 \mathrm{E}-02$ \\
\hline Chromate $\mathrm{CrO}_{4}$ & $7.50 \mathrm{E}-02$ & $2.25 \mathrm{E}-01$ & $3.00 \mathrm{E}-01$ & 4.00E-02 \\
\hline Molybdate $\mathrm{MoO}_{4}$ & $2.50 \mathrm{E}-02$ & $2.50 \mathrm{E}+00$ & $5.00 \mathrm{E}-01$ & $1.58 \mathrm{E}-01$ \\
\hline Manganate $\mathrm{MnO}_{4}$ & $3.75 \mathrm{E}-01$ & - & $1.25 \mathrm{E}-01$ & $7.50 \mathrm{E}-01$ \\
\hline Arsenate $\mathrm{AsO}_{4}$ & $9.00 \mathrm{E}-02$ & $2.00 \mathrm{E}-01$ & $5.75 \mathrm{E}-01$ & $2.75 \mathrm{E}-01$ \\
\hline \multicolumn{5}{|l|}{ Other sulfur compounds } \\
\hline Tetrathionate $\mathrm{S}_{4} \mathrm{O}_{6}$ & 1.00E-05 & $4.00 \mathrm{E}-04$ & $5.00 \mathrm{E}-04$ & $5.00 \mathrm{E}-03$ \\
\hline Peroxidisulfate $\mathrm{S}_{2} \mathrm{O}_{8}$ & $1.25 \mathrm{E}-03$ & 1.15E-03 & $6.75 \mathrm{E}-03$ & $6.00 \mathrm{E}-03$ \\
\hline Succinaldehyde bisulfite & $7.50 \mathrm{E}+00$ & $1.50 \mathrm{E}+01$ & $1.50 \mathrm{E}+00$ & $5.50 \mathrm{E}+00$ \\
\hline Glutaraldehyde bisulfite & 5.00E-02 & $2.50 \mathrm{E}+00$ & $8.75 \mathrm{E}-01$ & $3.00 \mathrm{E}+00$ \\
\hline \multicolumn{5}{|l|}{ Miscellaneous compounds } \\
\hline Phenylphosphate & 5.00E-06 & $1.00 \mathrm{E}-03$ & 1.13E-02 & $1.50 \mathrm{E}-02$ \\
\hline Rhodizonate & $1.05 \mathrm{E}-01$ & $5.00 \mathrm{E}-01$ & $3.75 E+00$ & $1.25 \mathrm{E}-01$ \\
\hline Hydrogen phosphite & $3.25 \mathrm{E}-02$ & $2.00 \mathrm{E}-01$ & $1.00 \mathrm{E}+00$ & $3.50 \mathrm{E}-02$ \\
\hline Selenite & $7.50 \mathrm{E}-02$ & - & 7.00E-02 & $2.63 \mathrm{E}+00$ \\
\hline
\end{tabular}

* Limit of detection determined where the amount of analyte used results in $\mathrm{S} / \mathrm{N}=3$.

Bold typeface indicates the lowest limit of detection for each anion.

- Indicates that a dianion/trication complex was not observed.

pattern for bromine (Figure 4c) is evidence of the gas-phase association of the bromine with a +2 fragment of the trication. The improvement in LOD between SIM and SRM was larger for the halogenated dicarboxylates using the trigonal trications.

Phenylphosphate showed an improvement of 2-3 orders of magnitude by SRM for both linear trications. The SRM LODs for the dicarboxylates ranged from just slightly better than SIM LODS to about 8 times better, with the exception of fumarate and malonate which showed 18-fold (LTC 2) and 20-fold (LTC 1) improvements, respectively. Arsenate (LTC 2), hexachlororhenate (LTC 2, TTC 1), and glutaraldehyde bisulfite (LTC 1) were the only other analytes with improvements of an order of magnitude or more. In general, the linear trications had lower LODs for SRM than the trigonal cations.

The tricationic reagents can pair with doubly charged anions to form complexes with an overall +1 charge, but can also pair with singly charged anions to form +2 complexes. Five "mono-anions" were evaluated using the four tricationic reagents to determine their limits of detection. The data for SIM and SRM for these anions is shown in Table 3. The LOD for benzenedisulfonate both by SIM and SRM is the lowest for the five singly charged anions tested. In comparison to the SIM LOD for the dicationic reagents tested in a previous study [43], the LOD for benzenedisulfonate ranks second using LTC 1 as a pairing reagent. The LODs in this study for perfluorooctanate and mono- 


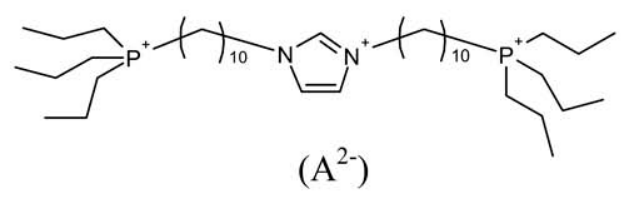

(a)
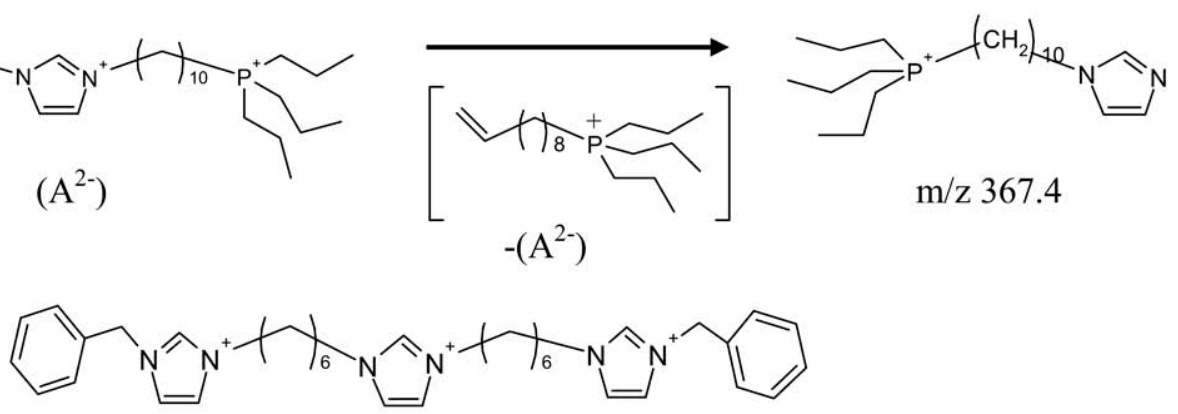

$\left(\mathrm{A}^{2-}\right)$

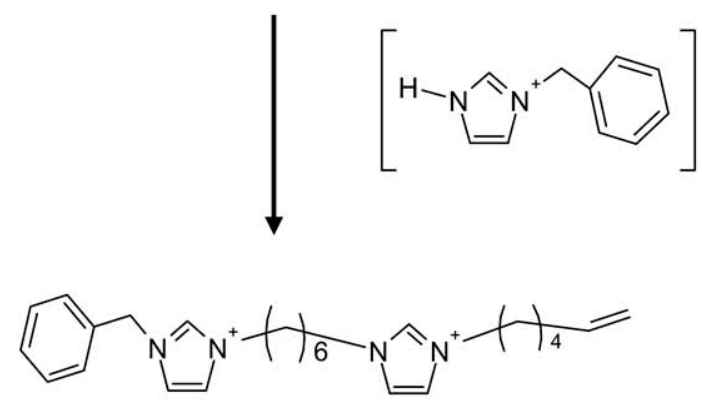

(b)

$\left(\mathrm{HA}^{-}\right)$

Figure 3. Proposed fragmentation pathways for the disulfonates using LTC 1 (a) and LTC 2 (b). $\mathrm{A}^{2-}$ represents a general divalent anion and $\mathrm{HA}^{-}$is a singly protonated divalent anion.

chloroacetate are better than 7 to 8 (of 23) of the dicationic pairing reagents previously studied [43]. The ability of the tricationic reagents to pair with doubly and singly charged anions shows that the use of a single tricationic pairing reagent could be used to evaluate both monovalent and divalent anions simultaneously.

The LODs in this study compare favorably with those reported for anion analysis by other methods. There are many methods reported for the analysis of biologically relevant organic acids. In our study, the LODs for fumarate and methylsuccinate were 10 and 24 $\mathrm{pg}$, respectively. Lower limits were determined, $0.9 \mathrm{pg}$ fumarate and $0.5 \mathrm{pg}$ methylsuccinate, by an LC method where the analytes were subjected to a long derivatization process to use fluorescence detection [21]. CE analysis with indirect UV detection was used to determine levels of various organic acids. The LODs under the optimized CE conditions for malonic acid, methylsuccinic acid, glutaric acid, and adipic acid reported are $144,37.3,34.9$, and $72.2 \mathrm{pg}$, respectively. Our SRM tricationic method showed lower LODs for the malonic and methylsuccinic acids (100 and $24 \mathrm{pg}$ ), similar results for the glutaric acid (37.5 pg), and higher results for adipic acid (120 pg) [24]. A number of the analytes in that study had very similar migration times and, without a more specific detection method, might be indistinguishable in that analysis.

Larger improvements over previous methods were seen with the disulfonates. A LOD of $200 \mathrm{pg}$ for benzenedisulfonate by LC-UV was reported [19]. Using our method and TTC 1, the LOD for the same analyte is $8.75 \mathrm{pg}$ using SIM detection and $500 \mathrm{fg}$ using LTC 1 and SRM detection. Other aromatic sulfonates were determined in concentration ranges of $0.1-1 \mathrm{ng} / \mathrm{mL}$ by solid-phase extraction-ion pair chromatography using UV detection [11] and 100-400 $\mathrm{ng} / \mathrm{mL}$ by CE/MS [3]. The LOD for napthalene-1,5-disulfonic acid was determined by ion interaction chromatography both by the direct injection of a large sample volume $(100 \mathrm{uL})$ and preconcentration (sample volume of $50 \mathrm{~mL}$ ) [16]. The LODs were $20 \mathrm{ng}$ for the large sample volume and $30 \mathrm{ng}$ for the sample preconcentration. Using the tricationic pairing method and no preconcentration, the LOD for this analyte is $12.5 \mathrm{pg}$ in SIM mode and $461 \mathrm{fg}$ in SRM.

The analysis of inorganic ions is also important, though not always as facile as the detection of organic acids or disulfonates. A coated-wire membrane sensor electrode was used to determine chromate levels in solution [48]. The LOD for this method was determined in a solution that was $116 \mathrm{ng} / \mathrm{mL}$. In our analysis of chromate, the lowest solution concentration we analyzed was $8 \mathrm{ng} / \mathrm{mL}$ in SRM mode using TTC 2, for an absolute detection limit of $40 \mathrm{pg}$. Molybdate levels in various water samples were determined by coprecipitation and neutron activation analysis, a very labor intensive technique that can necessitate the use of a reactor [49]. The limit of detection for this method was $1 \mathrm{pg} / \mathrm{mL}$ using a $100 \mathrm{~mL}$ sample, for an absolute detection of $100 \mathrm{pg}$ of molybdate. Using LTC 1 , the LOD for molybdate in SRM is $25 \mathrm{pg}$. Another precipitation 


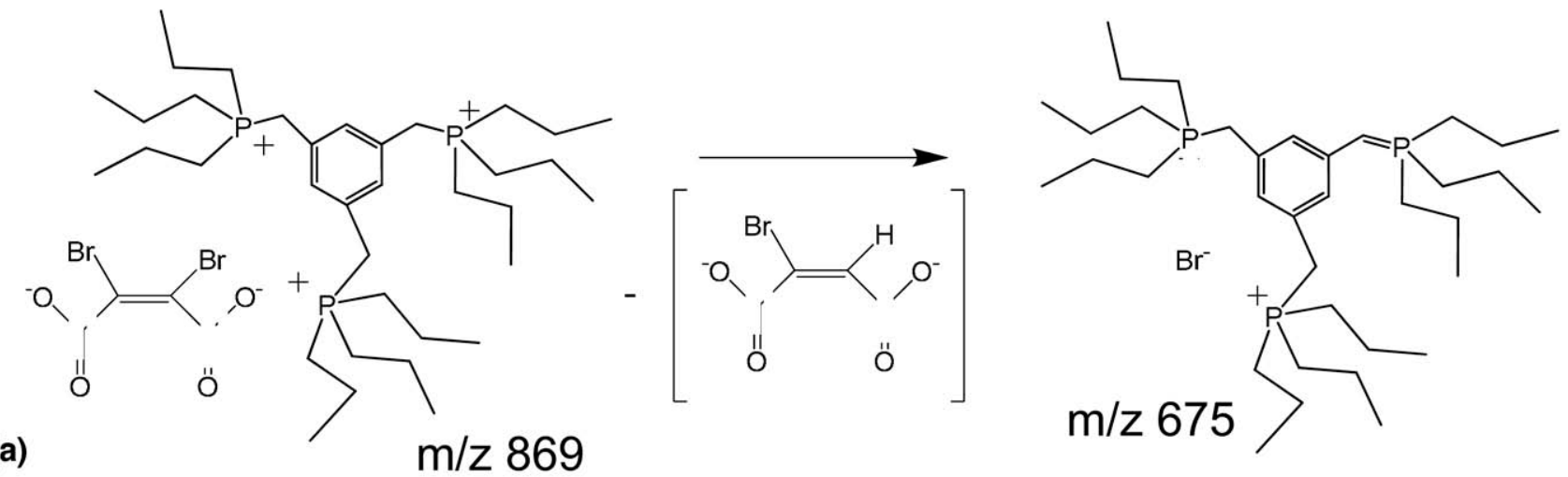

(a)

$\mathrm{m} / \mathrm{z} 869$

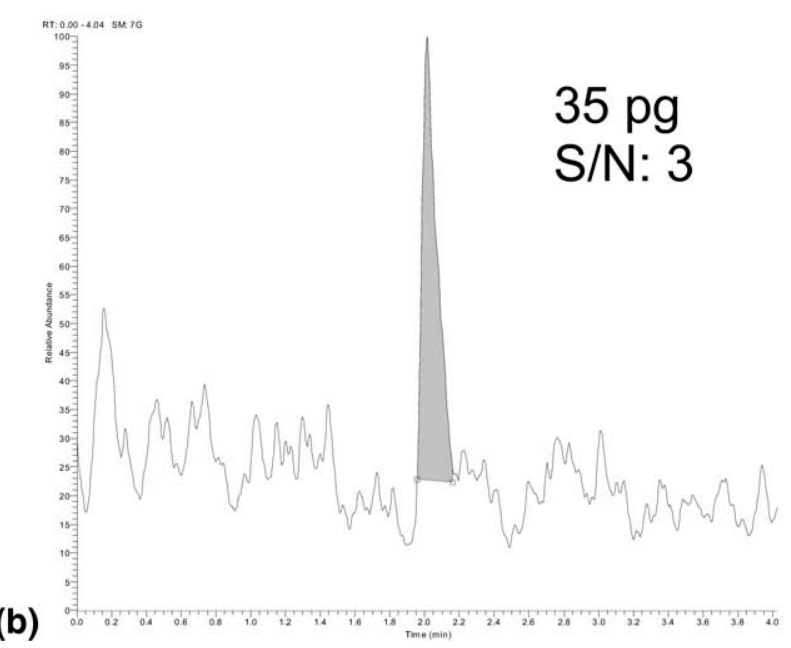

(c)

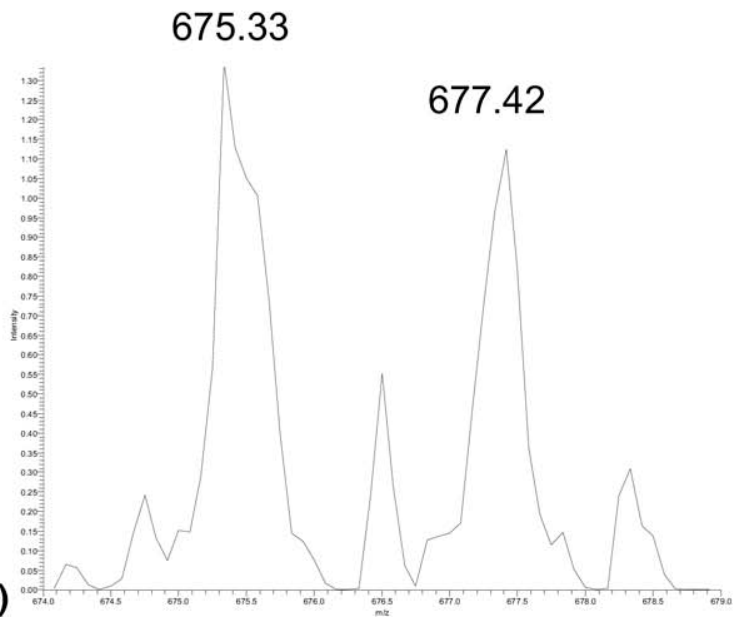

Figure 4. Proposed fragmentation pathway of the SRM transition for dibromomaleate (a). Panel (b) shows an injection monitoring the SRM transition from $\mathrm{m} / \mathrm{z}$ 869à to 675.33 and 677.42. Panel (c) is the fragment spectrum observed for the peak shown in (b). The main peaks are two mass units apart and nearly the same height, indicative of Br.

method was used to preconcentrate $\mathrm{ReCl}_{6}$ followed by detection using selective excitation of probe ion luminescence [50]. In this study, $150 \mathrm{pg}$ of $\mathrm{ReCl}_{6}$ was needed to see an observable signal. In our study, $\mathrm{ReCl}_{6}$ was determined well below $150 \mathrm{pg}$ in both SIM (15 pg) and SRM (2 pg) monitoring modes.

\section{Conclusions}

Four optimal tricationic pairing reagents were used to determine the limits of detection for 34 divalent anions and five monovalent anions. The linear and trigonal tricationic reagents performed about equally as a

Table 3. LODs in SIM and SRM modes for monovalent anions using four tricationic pairing reagents*

\begin{tabular}{|c|c|c|c|c|}
\hline \multirow[b]{2}{*}{ SIM mode } & \multicolumn{2}{|c|}{ Linear trications } & \multicolumn{2}{|c|}{ Trigonal trications } \\
\hline & $\begin{array}{c}\text { LTC } 1 \\
\text { LOD (ng) }\end{array}$ & $\begin{array}{c}\text { LTC } 2 \\
\text { LOD (ng) }\end{array}$ & $\begin{array}{c}\text { TTC } 1 \\
\text { LOD (ng) }\end{array}$ & $\begin{array}{c}\text { TTC } 2 \\
\text { LOD (ng) }\end{array}$ \\
\hline Benzenesulfonate & $1.50 \mathrm{E}-03$ & $9.00 \mathrm{E}-03$ & $1.50 \mathrm{E}-02$ & $3.13 \mathrm{E}-03$ \\
\hline Perfluorooctanoate & $5.00 \mathrm{E}-02$ & $2.75 \mathrm{E}-02$ & $1.50 \mathrm{E}-02$ & $5.00 \mathrm{E}-02$ \\
\hline Trifluoromethanesulfonimide & 1.05E-02 & 7.50E-02 & $3.00 \mathrm{E}-02$ & $1.00 \mathrm{E}-01$ \\
\hline Monochloroacetate & $7.00 \mathrm{E}+00$ & $1.25 \mathrm{E}+01$ & $1.00 \mathrm{E}-01$ & $2.00 \mathrm{E}+00$ \\
\hline Benzoate & $6.25 \mathrm{E}+01$ & $8.75 E+00$ & $3.75 \mathrm{E}+00$ & 9.65E-02 \\
\hline SRM mode & LOD (ng) & LOD (ng) & LOD (ng) & $\operatorname{LOD}(\mathrm{ng})$ \\
\hline Benzenesulfonate & $9.50 \mathrm{E}-05$ & $2.70 \mathrm{E}-03$ & $3.50 \mathrm{E}-03$ & $1.38 \mathrm{E}-03$ \\
\hline Perfluorooctanoate & 3.00E-04 & 4.13E-03 & $3.00 \mathrm{E}-03$ & 1.63E-03 \\
\hline Trifluoromethanesulfonimide & $1.05 \mathrm{E}-02$ & $6.00 \mathrm{E}-02$ & $2.50 \mathrm{E}-02$ & 3.43E-04 \\
\hline Monochloroacetate & - & $1.00 \mathrm{E}+01$ & $1.00 \mathrm{E}-02$ & 7.50E-02 \\
\hline Benzoate & - & $8.75 E+00$ & $3.75 \mathrm{E}-01$ & 9.65E-02 \\
\hline
\end{tabular}

* Limit of detection determined where the amount of analyte used results in $\mathrm{S} / \mathrm{N}=3$.

Bold typeface indicates the lowest limit of detection for each anion.

- Indicates that a dianion/trication complex was not observed. 
whole, but the two trications with tripropylphosphonium cationic moieties outperformed trications with imidazolium based charge groups. When evaluating tricationic reagents, our results show that the linear trications provide lower limits of detection for most classes of compounds and should be tested first. The exception to this is the determination of disulfonates, where trigonal trications generally perform better. The use of tandem MS on the trication/di-anion complex helps to improve the sensitivity of detection for most of the dianions studied. Those complexes that dissociate into fragments not common to the trication showed the lowest limits of detection. Tricationic ion-pairing agents can also be used to determine monovalent anions by monitoring the +2 complexes. Therefore, mixtures of monovalent and divalent anions could be studied using a single tricationic reagent. Many of the LODs in this study are better or similar to those that have been previously reported, however this method is advantageous as it does not involve intricate sample preparation or preconcentration and may be accessible to more laboratories.

\section{Acknowledgments}

The authors gratefully acknowledge the Robert A. Welch Foundation for its financial support.

\section{References}

1. Brooks Avery, J. G.; Kieber, R. J.; Witt, M.; Willey, D. Rainwater Monocarboxylic and Dicarboxylic Acid Concentrations in Southeastern North Carolina, USA, as a Function of Air-Mass Back-Trajectory. Atmos. Environ. 2006, 40(9), 1683-1693.

2. Liu, A.; Kushnir, M. M.; Roberts, W. L.; Pasquali, M. Solid Phase Extraction Procedure for Urinary Organic Acid Analysis by Gas Chromatography Mass Spectrometry. J. Chromatogr. B 2004, 806(2), 283-287.

3. Loos, R.; Riu, J.; Alonso, M. C.; Barceló, D. Analysis of Polar Hydrophilic Aromatic Sulfonates in Waste Water Treatment Plants by CE/MS and LC/MS. J. Mass Spectrom. 2000, 35(10), 1197-1206.

4. Fung, Y. S.; Kap, M. L. Analysis of organic acids and inorganic anions in beverage drinks by capillary electrophoresis. Electrophoresis 2003, 24(18), 3224-3232.

5. Fung, Y.S.; Tung, H.S. Application of Capillary Electrophoresis for Organic Acid Analysis in Herbal Studies. Electrophoresis 2001, 22(11), 2242-2250.

6. Blount, B. C.; Valentin-Blasini, L. Analysis of Perchlorate, Thiocyanate, Nitrate, and Iodide in Human Amniotic Fluid Using Ion Chromatography and Electrospray Tandem Mass Spectrometry. Anal. Chim. Acta 2006, 567(1), 87-93.

7. Dietz, E. A.; Singley, K. F. Determination of Fumaric Acid, Maleic Acid, and Phthalic Acid in Groundwater and Soil. J. Liq. Chromatogr. 1994, 17(7), 1637-1651.

8. Kvasnicka, F.; Voldrich, M. Determination of Fumaric Acid in Apple Juice by On-Line Coupled Capillary Isotachophoresis-Capillary Zone Electrophoresis with UV Detection. J. Chromatogr. A 2000, 891(1), 175-181.

9. Kitami, H.; Ishihara, Y. Determination of Eight Organic Acids in Sake and Wine by Suppressed Ion Chromatography with Triacontyl Groups (C30) as a Stationary Phase. Kankyo Kagaku 2006, 16(4), 691-696.

10. Hagen, T.; Korson, M. S.; Sakamoto, M. Evans, E. A GC/MS/MS Screening Method for Multiple Organic Acidemias from Urine Specimens. Clin. Chim. Acta 1999, 283(1/2), 77-88.

11. Altenbach, B.; Giger, W. Determination of Benzene- and Naphthalenesulfonates in Waste Water by Solid-Phase Extraction with Graphitized Carbon Black and Ion-Pair Liquid Chromatography with UV Detection. Anal. Chem. 1995, 67(14), 2325-2333.

12. Dudoit, A.; Pergantis, S. A. Ion Chromatography in Series with Conductivity Detection and Inductively Coupled Plasma-Mass Spectrometry for the Determination of Nine Halogen, Metalloid, and Nonmetal Species in Drinking Water. J. Anal. At. Spectrom. 2001, 16(6), 575-580.

13. Urbansky, E. T.; Magnuson, M. L.; Freeman, D.; Jelks, C. Quantitation of Perchlorate Ion by Electrospray Ionization Mass Spectrometry (ESI-MS)
Using Stable Association Complexes with Organic Cations and Bases to Enhance Selectivity. I. Anal. At. Spectrom. 1999, 14(12), 1861-1866.

14. Dyke, J. V.; Kirk, A. B.; Kalyani-Martinelango, P.; Dasgupta, K. Sample Processing Method for the Determination of Perchlorate in Milk. Anal. Chim. Acta 2006, 567(1), 73-78.

15. Martinelango, P. K.; Guemues, G.; Dasgupta, K. Matrix Interference Free Determination of Perchlorate in Urine by Ion Association-Ion Chromatography-Mass Spectrometry. Anal. Chim. Acta 2006, 567(1), $79-86$

16. Sarzanini, C.; Bruzzoniti, M. C.; Sacchero, G.; Mentasti, E. On-Line Preconcentration and Separation of Neutral and Charged Aromatic Compounds by Ion Interaction Chromatography. J. Chromatogr. A 1996, 739(1/2), 63-70.

17. Marconi, O.; Floridi, S.; Montanari, L. Organic Acids Profile in Tomato Juice by HPLC with UV Detection. J. Food Qual. 2007, 30(2), 253-266.

18. Yoshida, H.; Mizukoshi, T.; Hirayama, K.; Miyano, H. Comprehensive Analytical Method for the Determination of Hydrophilic Metabolites by High-Performance Liquid Chromatography and Mass Spectrometry. J. Agric. Food Chem. 2007, 55(3), 551-560.

19. Jandera, P.; Fischer, J.; Prokes, B. HPLC Determination of Chlorobenzenes, Benzenesulphonyl Chlorides, and Benzenesulphonic Acids in Industrial Waste Water. Chromatographia 2001, 54(9/10), 581-587.

20. Hagberg, J. Analysis of Low-Molecular-Mass Organic Acids Using Capillary Zone Electrophoresis-Electrospray Ionization Mass Spectrometry. J. Chromatogr. A 2003, 988(1), 127-133.

21. Kubota, K.; Fukushima, T.; Yuii, R.; Miyano, H.; Hirayama, K.; Santa, T; Imai, K. Development of an HPLC-Fluorescence Determination Method for Carboxylic Acids Related to the Tricarboxylic Acid Cycle as a Metabolome Tool. Biomed. Chromatogr. 2005, 19(10), 788-795.

22. Al-Dirbashi, O. Y.; Jacob, M.; Al-Amoudi, M.; Al-Kahtani, K.; Al-Odaib, A.; El-Badaoui, F.; Rashed, S. Quantification of Glutaric and 3Hydroxyglutaric Acids in Urine of Glutaric Acidemia Type I Patients by HPLC with Intramolecular Excimer-Forming Fluorescence Derivatization. Clin. Chim. Acta 2005, 359(1/2), 179-188.

23. Kuijt, J.; de Rijke, E.; Brinkman, U. A. T.; Gooijer, C. Practical Implementation of Quenched Phosphorescence Detection in Capillary Electrophoresis. Anal. Chim. Acta 2000, 417(1), 15-17.

24. Chen, H.; Xu, Y.; Van Lente, F.; Ip, C. Indirect Ultraviolet Detection of Biologically Relevant Organic Acids by Capillary Electrophoresis. J. Chromatogr. B 1996, 679(1/2), 49-59.

25. Schneede, J.; Mortensen, J. H.; Kvalheim, G.; Ueland, M. Capillary Zone Electrophoresis with Laser-Induced Fluorescence Detection for Analysis of Methylmalonic Acid and Other Short-Chain Dicarboxylic Acids Derivatized with 1-Pyrenyldiazomethane. J. Chromatogr. A 1994, 669(1/ 2), 185-193.

26. Kappes, T.; Schnierle, P.C.; Hauser, P. Potentiometric Detection of Inorganic Anions and Cations in Capillary Electrophoresis with CoatedWire Ion-Selective Electrodes. Anal. Chim. Acta 1997, 350(1/2), 141-147.

27. Isildak, I. Potentiometric Detection of Monovalent Anions Separated by Ion Chromatography Using All Solid-State Contact PVC Matrix Membrane Electrode. Chromatographia 1999, 49(5/6), 338-342.

28. Isildak, I.; Asan, A. Simultaneous Detection of Monovalent Anions and Cations Using All Solid-State Contact PVC Membrane Anion and Cation-Selective Electrodes as Detectors in Single Column Ion Chromatography. Talanta 1999, 48(4), 967-978.

29. Chen, L.: Tian, X. Tian, L.; Liu, L.: Song, W: Xu, H. Electrochemical Reduction and Flow Detection of Iodate on (Bu4N)2Mo6O19 SelfAssembled Monolayer. Anal. Bioanal. Chem. 2005, 382(4), 1187-1195.

30. Salimi, A.; Mamkhezri, H.; Mohebbi, S. Electroless Deposition of Vanadium-Schiff Base Complex onto Carbon Nanotubes Modified Glassy Carbon Electrode: Application to the Low Potential Detection of Iodate, Periodate, Bromate, and Nitrite. Electrochem. Commun. 2006, 8(5), 688-696.

31. Buchberger, W. W. Detection Techniques in Ion Analysis: What are Our Choices? J. Chromatogr. A 2000, 884(1/2), 3-22.

32. Magnuson, M. L. Urbansky, E. T.; Kelty, A. Microscale Extraction of Perchlorate in Drinking Water with Low Level Detection by ElectrosprayMass Spectrometry. Talanta 2000, 52(2), 285-291.

33. Valentin-Blasini, L.; Mauldin, J. P.; Maple, D.; Blount, C. Analysis of Perchlorate in Human Urine Using Ion Chromatography and Electrospray Tandem Mass Spectrometry. Anal. Chem. 2005, 77(8), 2475-2481.

34. Cech, N. B.; Enke, C. G. Practical Implications of Some Recent Studies in Electrospray Ionization Fundamentals. Mass Spectrom. Rev. 2001, 20(6), 362-387.

35. Kebarle, P.; Ho, Y. In: Electrospray ionization mass spectrometry; Cole, R. B., Ed.; Wiley: New York, 1997, p. 14.

36. Cole, R. B.; Harrata, A. K. Charge-State Distribution and ElectricDischarge Suppression in Negative-Ion Electrospray Mass Spectrometry Using Chlorinated solvents. Rapid Commun. Mass Spectrom. 1992, $6(8), 536-539$

37. Cole, R. B.; Zhu, J. Chloride Anion Attachment in Negative Ion Electrospray Ionization Mass Spectrometry. Rapid Commun. Mass Spectrom. 1999, 13(7), 607-611.

38. Apffel, A.; Chakel, J. A.; Fischer, S.; Lichtenwalter, K.; Hancock, S Analysis of Oligonucleotides by HPLC-Electrospray Ionization Mass Spectrometry. Anal. Chem. 1997, 69(7), 1320-1325.

39. Straub, R. F.; Voyksner, R. D. Negative Ion Formation in Electrospray Mass Spectrometry. J. Am. Soc. Mass Spectrom. 1993, 4(7), 578-587.

40. Martinelango, P. K.; Anderson, J. L.; Dasgupta, P. K.; Armstrong, D. W.; Al-Horr, R. S.; Slingsby, W. Gas-Phase Ion Association Provides In- 
creased Selectivity and Sensitivity for Measuring Perchlorate by Mass Spectrometry. Anal. Chem. 2005, 77(15), 4829-4835.

41. Martinelango, P. K.; Tian, K.; Dasgupta, K. Perchlorate in Sea Water. Anal. Chim. Acta 2006, 567(1), 100-107.

42. Soukup-Hein, R. J.; Remsburg, J. W.; Dasgupta, P. K.; Armstrong, W. A General, Positive Ion Mode ESI-MS Approach for the Analysis of Singly Charged Inorganic and Organic Anions Using a Dicationic Reagent. Anal. Chem. 2007, 79(19), 7346-7352.

43. Remsburg, J. W.; Soukup-Hein, R. J.; Crank, J. A.; Breitbach, Z. S.; Payagala, T.; Armstrong, W. Evaluation of Dicationic Reagents for Their Use in Detection of Anions Using Positive Ion Mode ESI-MS Via Gas Phase Ion Association. I. Am. Soc. Mass Spectrom. 2008, 19(2), 261-269.

44. Soukup-Hein, R. J.; Remsburg, J. W.; Breitbach, Z. S.; Sharma, P. S.; Payagala, T.; Wanigasekara, E.; Huang, J.; Armstrong, W. Evaluating the Use of Tricationic Reagents for the Detection of Doubly Charged Anions in the Positive Mode by ESI-MS. Anal. Chem. 2008, 80(7), 2612-2616

45. Breitbach, Z. S.; Warnke, M. M.; Wanigasekara, E.; Zhang, X.; Armstrong, D. W. Evaluation of Flexible Linear Tricationic Salts as Gas-
Phase Ion-Pairing Reagents for the Detection of Divalent Anions in the Positive Mode ESI-MS. Anal. Chem. 2008, in press.

46. Wanigasekara, E.; Zhang, X.; Nanayakkra, Y.; Moon, H.; Armstrong, W Novel Linear Tricationic Room Temperature Ionic Liquids: Synthesis, Properties and Applications. Chem. Mat. 2008, unpublished.

47. Sharma, P. S.; Payagala, T.; Wanigasekara, E.; Wijeratne, A. B.; Huang, J.; Armstrong, D. W. Trigonal Tricationic Ionic Liquids: Molecular Engineering of Trications to Control Physiochemical Properties. Chem. Mat. 2008, 20(13), 4182-4184

48. Ardakani, M. M.; Dastanpour, A.; Salavati-Nisari, M. Novel CoatedWire Membrane Sensor Based on Bis(Acetylacetonato) Cadmium(II) for the Determination of Chromate Ions. Microchim. Acta 2005, 150(1), $67-72$.

49. Sun, Y. C.; Yang, J. Y; Tzeng, S. R. Rapid Determination of Molybdate in Natural Waters by Coprecipitation and Neutron Activation Analysis. Analyst 1999, 124(3), 421-424.

50. Haskell, R. J.; Wright, J. C. Determination of Rhenium at Ultratrace Levels by Selective Laser Excitation of Precipitates. Anal. Chem. 1985, 57(1), 332-336 